\title{
ANALISIS KEBUTUHAN DAN PENCARIAN INFORMASI IBU DENGAN KELAHIRAN ANAK PERTAMA PERIODE POSTPARTUM: STUDI KASUS WHATSAPP GROUP ZONA MAMA
}

\author{
Aji Subekti \\ UPT Perpustakaan Proklamator Bung Karno Kota Blitar \\ Korespondensi: abekti@gmail.com
}

Diajukan: 05-03-2019; Direview: 01-04-2019; Diterima: 16-05-2019; Direvisi: 23-09-2019

\begin{abstract}
This study aims to understand the needs and search for information from primiparous mothers, so that they can provide appropriate information and certainly can reduce maternal anxiety towards postpartum depression. The research method used is a case study on WhatsApp Group (WAG) Zona Mama. The result is that there is concern and anxiety from primiparous mothers in the postpartum phase. This happens because of a lack of information about topics such as breastfeeding, how to care for children, and complementary feeding provided by information providers such as health workers and librarians. Information searching that has been done so far using an active scanning model that is carrying out active information retrieval, but does not have a detailed plan. Therefore, it seems that information leaflets from information providers such as hospitals and libraries are needed by new mothers. Sometimes websites and forums are doubtful by mothers. They need an information center that is consistent and controlled by professional.
\end{abstract}

\begin{abstract}
ABSTRAK
Penelitian ini bertujuan untuk memahami kebutuhan dan pencarian informasi dari para ibu primipara sehingga dapat menyediakan informasi yang tepat dan tentu dapat mengurangi kecemasan ibu terhadap postpartum depresi. Metode penelitian yang digunakan adalah studi kasus pada WhatsApp Group (WAG) Zona Mama. Hasilnya adalah bahwa ada kekhawatiran dan kecemasan dari ibu primipara dalam fase postpartum. Hal ini terjadi karena kurangnya informasi tentang topik seperti ASI, cara merawat anak, dan MPASI yang diberikan oleh penyedia informasi seperti tenaga kesehatan dan pustakawan. Pencarian informasi yang selama ini dilakukan menggunakan model pemindai aktif yaitu melaksanakan pencarian informasi yang aktif, akan tetapi tidak memiliki rencana secara mendetail. Selebaran informasi dari lembaga penyedia informasi seperti rumah sakit dan perpustakaan sangat diperlukan oleh ibu baru melahirkan. Terkadang laman web dan forum diragukan keandalan oleh para ibu. Mereka membutuhkan suatu pusat informasi yang konsisten dan dikendalikan oleh para professional.
\end{abstract}

Keywords: Information needs; Information retrieval; Psychology; WhatsApp; Postpartum; Mother zone

\section{PENDAHULUAN}

Kehamilan dan persalinan adalah dua tahap penting dalam kehidupan wanita. Periode postpartum adalah waktu yang menegangkan dalam kehidupan seorang wanita karena secara tiba-tiba dan intens terjadi perubahan dalam peran dan tanggung jawab wanita tersebut. Postpartum merupakan keadaan sesudah persalinan atau dapat juga disebut sebagai masa nifas. Mayoritas wanita tampaknya memiliki kecemasan dan ketakutan di sekitar pengasuhan dini dan perubahan-perubahan dalam fisik dan mental mereka. Kecemasan tersebut dalam istilah kesehatan disebut sebagai depresi postpartum. Depresi postpartum merupakan suatu gejala klinik depresi yang terjadi pada wanita postpartum. Depresi ini umumnya timbul pada tiga sampai empat belas hari sesudah melahirkan, bahkan dapat menetap beberapa bulan. Bila 
tidak mendapat penanganan yang cukup dapat berlangsung dua sampai tiga tahun sesudah melahirkan.

Munculnya gejala postpartum blues perlu diperhatikan baik oleh keluarga maupun pihak penyedia layanan kesehatan. Perhatian terhadap keadaan psikologis yang kurang, menyebabkan ibu cenderung mencoba mengatasi permasalahannya sendiri sehingga lebih rentan mengalami postpartum blues. Gangguan perasaan khususnya bagi para ibu yang baru melahirkan seperti halnya postpartum blues dapat menimbulkan masalah pada ibu itu sendiri, bayinya serta pada keluarganya khususnya suami.

Dampak yang terjadi pada ibu antara lain ibu mengalami gangguan aktivitas, gangguan berhubungan dengan orang lain (keluarga dan teman), dan ibu mungkin tidak dapat merawat diri sendiri dan bayinya. Dampak secara kesehatan yaitu ibu tidak dapat mengikuti anjuran kesehatan selama masa nifas dan hal ini dikhawatirkan akan menimbulkan komplikasi ibu nifas yang lain. Dampak pada bayi yaitu bayi cenderung sering menangis, mengalami masalah tidur, dan gangguan makan. Dampak lain dari depresi postpartum adalah mempengaruhi kemampuan bayi dalam perkembangan bahasa, kedekatan emosional dengan orang lain, dan masalah bersikap (Hanifah, Roidatus Salma: 2017). Dampak yang paling fatal adalah ibu ada keinginan untuk bunuh diri atau bahkan ingin membunuh bayinya.

Azmi dkk. (2016) mengatakan bahwa upaya yang lazim ditemukan di Indonesia dalam mengatasi depresi postpartum adalah hanya dalam bentuk saran dan nasihat agar ibu dan bayi menjaga kesehatan diri dan bayinya. Namun upaya tersebut tidak dilakukan secara komprehensif dan tidak terprogram serta bukan merupakan bagian dari pelayanan seutuhnya pada saat antenatal care (ANC). Perawatan standar yang dilakukan sesuai protap saat ini hanya melihat ibu dari segi fisik saja, belum memandang ibu dari segi psikologisnya, sehingga keluhan yang terkait psikologis tidak terpantau dan tidak teratasi. Hal ini dapat menimbulkan berbagai dampak pada masa nifas nantinya bagi ibu, bayi dan juga keluarga karena ketidaksiapan dengan peran mereka. Pemberian informasi dan mendampingi ibu lebih baik untuk persiapan postpartum yang akan dialaminya dan dapat mengetahui apa saja kebutuhan yang ibu inginkan selama proses kehamilan, persalinan dan pasca salin.

Loudon (2016) menyatakan bahwa dukungan informasi membantu ibu merasa siap dan percaya diri untuk peran baru mereka, dan memudahkan transisi dari orang tua mereka. Ibu dapat mempertimbangkan secara aktif bahwa pencarian informasi merupakan "bagian penting untuk mempersiapkan menjadi ibu", dan dengan sendirinya menyajikan tantangan baru. Penyediaan dukungan informasi yang memadai masih kurang dilakukan oleh para profesional baik itu dari tenaga kesehatan maupun penyedia informasi seperti pustakawan. Menurut Loudon (2016) bahwa 44 persen ibu di Skotlandia melaporkan kebutuhan informasi yang tidak terpenuhi selama perawatan antenatal, dan 39 persen selama perawatan pascamelahirkan. Penelitian lebih lanjut melaporkan kebutuhan informasi yang tidak terpenuhi, terutama di antara ibu muda pertama kali melahirkan (primipara).

Ghosh (2002) menyatakan bahwa pustakawan sebagai penjaga dan penyebar informasi di dalam organisasi, juga sebagai spesialis informasi yang memberikan kontribusi yang besar terhadap keberhasilan pelaksanaan proyek manajemen pengetahuan. Demikianlah permasalahan bagi para penyedia informasi seperti pustakawan, dimana mereka tidak memahami kebutuhan dan pencarian informasi dari para ibu primipara, padahal dengan memahami kebutuhan dan cara pencarian informasi tersebut dapat mengurangi kecemasan ibu terhadap postpartum depresi. Kajian ini berusaha untuk melaporkan temuan studi tentang 
kebutuhan dan pencarian informasi bagi ibu yang baru pertama kali melahirkan, sehingga mendapatkan pemahaman yang lebih baik tentang perkiraan kebutuhan dan perilaku pencarian informasi dari ibu yang baru pertama kali melahirkan tersebut.

\section{TINJAUAN PUSTAKA}

\subsection{Kebutuhan Informasi}

Wilson (1981) mengawali perkembangan konsep kebutuhan informasi. Wilson memulai pembahasannya dengan konsep dasar dari para ahli psikologi tentang kebutuhan manusia. Ia menyatakan bahwa kebutuhan manusia dibagi menjadi 3 kategori yaitu:

1) Kebutuhan fisiologis, seperti kebutuhan akan makanan, minuman, air dan tempat berlindung atau tempat tinggal

2) Kebutuhan afektif (lebih familiar disebut sebagai psikologis atau emosional), seperti kebutuhan untuk mendominasi, mencapai sesuatu, dan lainnya

3) Kebutuhan kognitif, seperti kebutuhan untuk merencanakan, dan meningkatkan kemampuan diri.

Berdasarkan ketiga kebutuhan di atas, Wilson menyatakan bahwa itu merupakan pemicu dari timbulnya kebutuhan informasi. Untuk memenuhi kebutuhan akan informasi tersebut, seseorang haruslah mencarinya, sehingga mereka harus terlibat dalam proses pencarian informasi. Wilson menganggap istilah kebutuhan informasi perlu ditambahkan sebagai proses pencarian informasi untuk mendapatkan kepuasan dari kebutuhannya. Wilson kemudian menuangkan kesimpulannya tersebut dalam Gambar 1.

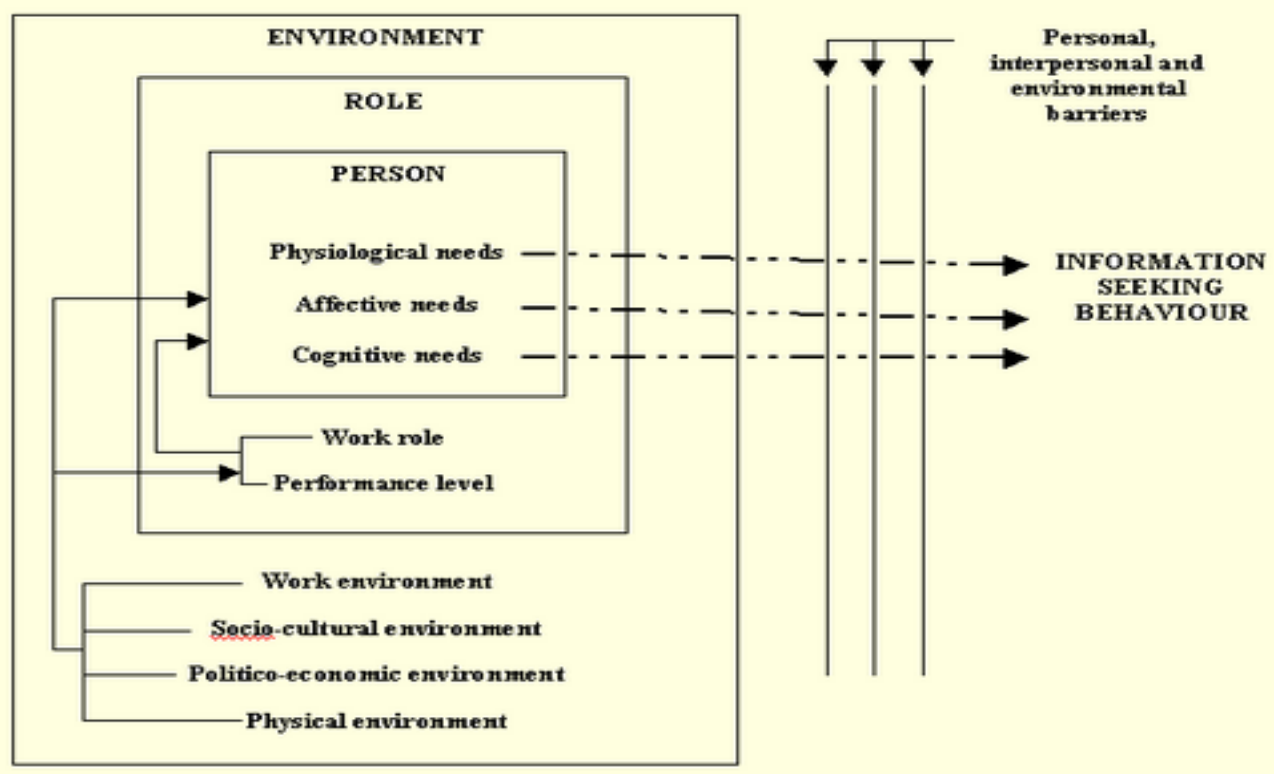

Gambar 1. Pola kebutuhan dan pencarian informasi (Wilson, 1981)

Berdasarkan Gambar 1, Wilson menjelaskan bahwa dalam kebutuhan informasi seseorang turut dipengaruhi oleh lingkungan (environment), seperti pekerjaan, sosial-budaya, politik-ekonomi dan lingkungan fisik. Peran dan posisi seseorang dalam suatu institusi juga turut mempengaruhi kebutuhan informasi. Sebagai contoh, seorang manajer biasanya lebih membutuhkan informasi mengenai topik manajemen dan kepemimpinan, daripada topik 
teknis. Informasi mengenai topik manajemen dan kepemimpinan diperlukan untuk menambah kapabilitas mereka, karena mereka mempunyai peran dan posisi sebagai seorang manajer.

Kebutuhan informasi juga dikaji oleh Chen di tahun 2014. Chen melakukan pengkajian di keluarga dengan pasien kanker. Hasil kajiannya menyatakan bahwa informasi yang dibutuhkan oleh keluarga tersebut adalah mengenai pola diet makanan, informasi spesifik tentang kanker, perawatan di rumah, informasi mengenai dukungan psikologis, kesehatan, ansuransi, kesejahteraan sosial bahkan sampai informasi mengenai pemakaman nanti.

Menurut Das dan Achary (2014), bahwa perpustakaan berusaha melakukan pengembangan dari koleksi, fasilitas, dan pelayanan untuk memenuhi kebutuhan informasi dari pemustaka. Hal tersebut penting dilakukan oleh setiap perpustakaan sebagai bentuk dari kepahaman dan kesadaran akan kebutuhan informasi, serta pola perilaku pencarian informasi dari pemustakanya.

\subsection{Pencarian Informasi}

McKenzie (2003) mempunyai empat konsep tentang praktik pencarian informasi. Pertama, pencarian aktif (active seeking) dimana praktik informasi paling terarah, karena informasi yang dicari sudah terindentifikasi, ditentukan dan pencariannya pun dilaksanakan dengan terencana dan sistematis. Kedua, pemindah aktif (active scanning) yaitu dengan mengindentifikasi sumber informasi yang sesuai, namun tidak terencana secara mendetail. Ketiga, pengawasan yang tidak terarah (non-directive monitoring) merupakan suatu pencarian dimana seseorang secara kebetulan mengenali dan memanfaatkan sumber informasi, seperti ketika membaca koran, dan kebetulan ketika membaca artikel tersebut dapat memenuhi kebutuhan informasinya. Keempat, by proxy yaitu ketika seseorang berinteraksi informasi melalui perantara. Model pencarian tersebut dijelaskan pada Gambar 2 .

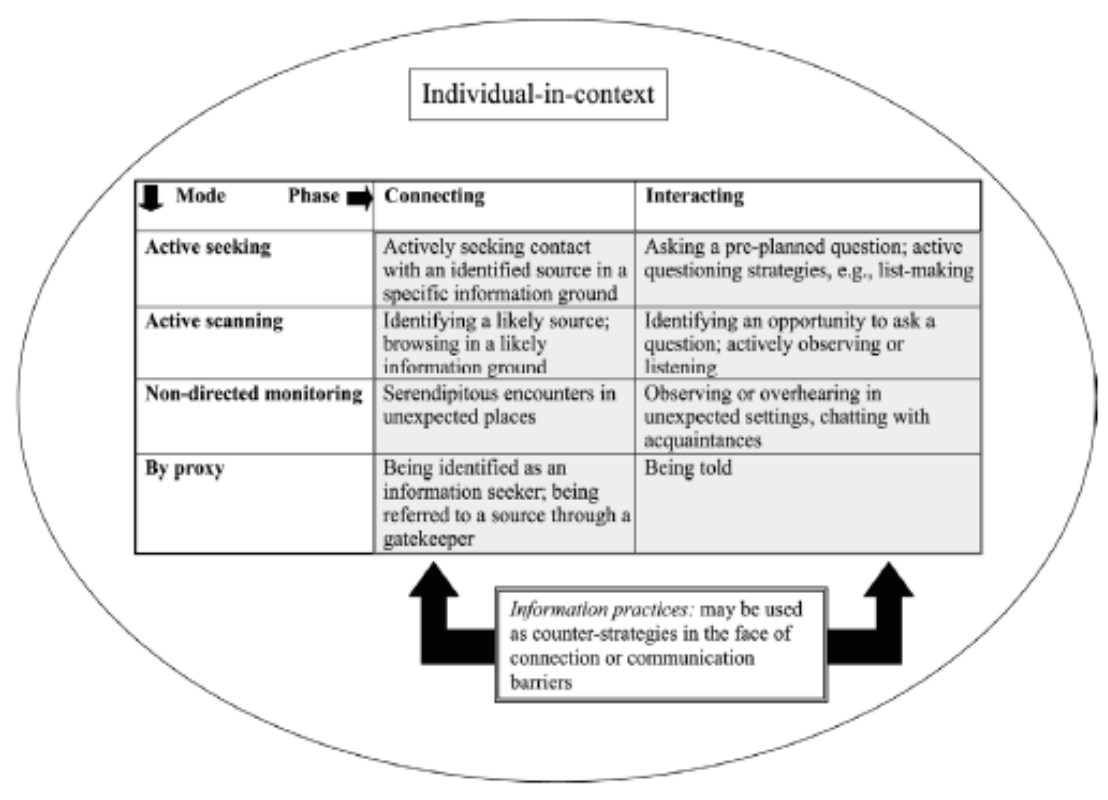

Gambar 2. Model pencarian dua dimensi (McKenzie, 2003) 
McKenzie (2003) menyatakan bahwa gejala yang khas dari pencarian informasi para ibu adalah "suatu praktik informasi aktif, insidental dan kebetulan yang berulang kali dapat digagalkan oleh rintangan". Rintangan yang dimaksud adalah kegagalan "menghubungkan", tidak mengungkapkan atau menghindar, dan sesi tanya jawab yang ragu-ragu. McKenzie memperingatkan bahwa unsur-unsur tertentu dari penelitiannya mungkin tidak berlaku untuk pengalaman ibu lainnya karena mereka terikat pada karakteristik fisik, kondisi sosial, umur, dan tingkat pendidikannya.

\section{METODE}

Penelitian ini menggunakan model penelitian deskriptif dengan pendekatan kualitatif. Metodenya adalah studi kasus sehingga menekankan pada pendalaman peristiwa, lingkungan, dan situasi tertentu yang memungkinkan mengungkapkan atau memahami suatu hal (Sulistyo- Basuki, 2010). Populasi penelitian ini adalah anggota grup dari WhatsApp Group (WAG) Zona Mama berjumlah 104 orang. Penentuan informan dilakukan dengan purposive sampling, yaitu teknik pengambilan sampel sumber data dengan pertimbangan dan tujuan tertentu. Kriterianya adalah ibu yang mengalami persalinan pertama kali (primipara) dalam WAG Zona Mama dengan jumlah 10 orang. Rahmawati (2018) menyatakan bahwa primipara merupakan ibu yang baru pertama kali melahirkan dan belum memiliki pengalaman dalam persalinan sehingga tingkat kecemasannya relatif lebih tinggi dibandingkan dengan ibu yang sudah pernah melahirkan. O'Hara \& Swain (1996) dalam Soep (2011) melaporkan ada sekitar 13\% wanita melahirkan anak pertama mengalami depresi nifas pada periode tahun pertama nifas. Teknik pengumpulan data dilakukan dengan observasi dan wawacara menggunakan WhatsApp. Analisis data mencakup transkip hasil wawancara, reduksi data, analisis, interpretasi data dan triangulasi. Sugiyono (2010) mengatakan bahwa dengan triangulasi, maka sebenarnya peneliti mengumpulkan data yang sekaligus menguji kredibilitas data, yaitu mengecek kredibilitas data dengan berbagai teknik pengumpulan data dan berbagai sumber data.

\section{HASIL DAN PEMBAHASAN}

Desfanita (2015) menjelaskan bahwa penyebab postpartum blues atau kecemasan ibu baru melahirkan belum diketahui secara pasti. Kondisi tersebut dipengaruhi dua faktor yaitu faktor internal dan faktor eksternal. Faktor internal yang mempengaruhi terjadinya postpartum blues, antara lain fluktuasi hormonal, faktor psikologis dan kepribadian, adanya riwayat depresi sebelumnya, riwayat kehamilan dan persalinan dengan komplikasi, persalinan sectio caesarea kehamilan yang tidak direncanakan, bayi berat badan lahir rendah.

WAG Zona Mama yang dibuat pada 2017, berusaha untuk membantu meringankan kecemasan dan kebingungan para ibu agar mendapatkan informasi mengenai kehamilan, melahirkan dan merawat anak. WAG ini dibina oleh Ibu Menik Haryani, seorang Konselor Laktasi dan MPASI yang berpendidikan Profesi Keperawatan (NERS). Ibu Menik merasa perihatin terhadap kondisi beberapa ibu yang tidak mempunyai biaya untuk melakukan konsultasi di lembaga kesehatan seperti rumah sakit dan klinik. Informasi yang diberikan Ibu Menik tidak dikenakan biaya, baik konsultasi yang bersifat offline di dalam kelas, kunjungan ke rumah, maupun online melalui WhatsApp. Sampai penelitian ini dilakukan WAG ini sudah beranggotakan 104 orang dari berbagai macam daerah dan latar belakang. 


\subsection{Kebutuhan Informasi}

Aston (2018) menyatakan bahwa sebenarnya periode postpartum awal adalah pengalaman hidup yang menyenangkan, namun juga menegangkan bagi ibu yang baru pertama kali melahirkan. Pada periode postpartum awal, ibu sering beralih ke keluarga, teman, dan profesional keperawatan untuk mendapatkan dukungan dan informasi.Akan tetapi dengan perkembangan teknologi komunikasi dan informasi seperti media sosial saat ini, terlihat berbeda karena sumber daya dan media sosial dapat menjadi sarana untuk memenuhi dukungan dan kebutuhan informasi ibu dan keluarga. Mayoritas informan merasa bahwa ketika sudah melahirkan pertama kali muncul kecemasan atau kekhawatiran dalam dirinya mengenai kemampuannya untuk menjadi seorang ibu yang baik. Informan Rizka, Yudhitia, dan Jumi mengatakan hal sama bahwa:

"Takut tidak dapat mengurus anaknya, baby blues ya"

"Tidak dapat mengurus anak dengan baik"

"Tidak mampu merawatnya"

Informan Mutiara menyatakan bahwa takut tidak dapat merawat anaknya nanti dan merasa rendah diri jika ada di hadapan suaminya karena perubahan bentuk badan. Bahkan informan Siti mengatakan ketakutan dan bingung kalau mendengar bayi menangis. Sebagian informan yang lain menyatakan khawatir tidak dapat memberikan ASI eksklusif kepada anaknya.

Topik yang paling sering dilontarkan oleh informan adalah cara merawat anak, baby blues ASI dan Makanan Pendamping ASI (MPASI). Slomean (2017) menyatakan bahwa mayoritas ibu, baik ibu yang pertama kali melahirkan maupun telah beberapa kali melahirkan, menyatakan bahwa informasi yang dibutuhkan adalah "informasi medis". Dalam kondisi sehat, mereka tetap membutuhkan informasi medis dari ahli kesehatan untuk memastikan bahwa semuanya baik-baik saja. Ketika ada masalah khusus (masalah makan, demam, sakit kuning, puncak pertumbuhan, kolik, sembelit, tumbuh gigi dan lain sebagainya), mereka lebih tenang jika berkonsultasi dengan professional kesehatan. Bahkan ibu yang sudah memiliki satu anak atau lebih, tetap membutuhkan informasi tentang apa yang belum pernah mereka alami dengan anak pertama mereka. Walaupun demikian, ibu primipara tetap lebih banyak membutuhkan informasi medis, karena belum adanya pengalaman dan pengetahuan tentang periode postpartum.

Guerra-reyes (2016) menyatakan empat bidang kebutuhan informasi yang mengarah pada pencarian informasi di postpartum awal yaitu pembentukan menyusui, masalah menyusui (lidah dasi dan bibir dasi), masalah kesehatan dan perilaku umum, dan topik-topik yang menurut sebagian orang sulit atau tidak nyaman untuk didiskusikan dengan penyedia layanan kesehatan. Perpustakaan sebagai salah satu institusi pusat informasi harus menyadari bahwa untuk memenuhi kebutuhan informasi ibu primipara tidak hanya menjadi tanggung jawab instansi kesehatan. Perpustakaan juga mempunyai peran untuk memenuhi kebutuhan informasi dari ibu primipara. Ibu primipara memerlukan informasi yang luas untuk dapat merawat diri mereka sendiri dan bayi mereka. Oleh karena itu, perpustakaan perlu mengindentifikasi dan mempertimbangkan kebutuhan informasi mereka.

Fungsi yang melekat pada perpustakaan sebagai sumber infomasi tidak hanya menyediakan ruang baca, tetapi juga dapat menjadi penyedia informasi yang dapat berkolaborasi dengan pusat informasi lainnya sehingga menghasilkan informasi yang valid dan konsisten. Menurut Rotich (2017), ada kesenjangan dan kontradiksi dalam pemberian informasi kepada ibu primipara karena banyaknya perbedaan informasi yang diterima. Oleh 
karena itu, perlu ada peningkatan komunikasi dan kolaborasi antara penyedia layanan kesehatan, pustakawan, praktisi kesehatan, dengan pembuat kebijakan.

\subsection{Pencarian Informasi}

Untuk mengatasi kecemasan ibu setelah melahirkan, informan melakukan berbagai cara, yaitu:

1) Meminta pendampingan dari suami dan tenaga kesehatan

2) Berdoa dan sering berpikir positif

3) Membaca artikel-artikel dengan browsing di web

4) Mengikuti grup-grup atau komunitas ibu, baik itu yang bersifat offline atupun online

Slomian (2017) menyatakan sulitnya menjadi seorang ibu. Ini terutama berlaku untuk ibu yang baru pertama kali melahirkan. Slomian mengatakan bahwa itu tidak selalu mudah beradaptasi dengan peran baru ibu dan bahwa mereka sering merasa kewalahan. Ada idealisasi keibuan seperti itu sehingga mereka tidak berani berbicara atau mengeluh tentang masalah mereka. Keberanian untuk berbicara dan mengeluh ketika mereka menemukan bahwa banyak ibu lain dalam situasi yang sama.

Guerra-reyes (2016) menjelaskan bahwa mayoritas wanita menggunakan aplikasi seluler untuk mendapatkan informasi mengenai kesehatan selama kehamilan. Mereka kurang memperhatikan informasi mengenai postpartum. Hendaknya aplikasi yang berisi informasi pascapartum harus dikembangkan dan gratis. Tampilan dari isi aplikasi tersebut hendaknya relevan dan selaras dengan usia anak, serta memberi pengguna kemampuan untuk menautkan ke situs web eksternal yang telah tervalidasi untuk mendapatkan informasi lebih rinci tentang topik tertentu yang diminati. Mengingat tingginya tingkat kebutuhan informasi tentang menyusui, hendaknya aplikasi seluler dapat memberikan simulasi praktis agar dapat dipahami oleh ibu.

Kaye (1995) menyatakan bahwa perpaduan komputer dan komunikasi telah membawa perubahan besar dalam aksesibilitas dan pemrosesan informasi. Sistem ini sekarang mengizinkan transfer informasi formal dan informal ke seluruh dunia dalam skala besar, melalui transmisi data satelit, konferensi video, surat elektronik dan sejenisnya, selain sistem telepon dan faksimile. Seseorang dapat mengakses database dari lokasi yang jauh, memilih informasi yang mereka butuhkan dan mengunduhnya ke dalam sistem komputer mereka sendiri untuk pemrosesan dan analisis lebih lanjut. Pada sektor informal, internet adalah fasilitas terbaru dan terkini. Internet adalah kumpulan ribuan jaringan komputer yang menghubungkan organisasi akademis, komersial dan pemerintah di seluruh dunia.

Menurut semua informan, WAG Zona Mama sangat membantu sekali dalam mengurangi tingkat kecemasan dan kebingungan informan yang baru menjadi ibu. Informan mengatakan ada beberapa alasan kenapa WAG Zona Mama dapat mengurangi kecemasannya, diantaranya:

1) banyak mendapatkan ilmu baru yang logik;

2) saling berbagi pengalaman antara anggotanya;

3) jawaban pengasuh grup yang responsif

Slomian (2017) menyatakan bahwa sebagian besar ibu perlu berbagi pengalaman mereka, menjadi ibu baru, dengan keluarga atau teman. Banyak ibu lebih suka berdiskusi dengan wanita yang sudah menjadi ibu (dalam jaringan keluarga atau teman). Mereka menyatakan bahwa perlu membandingkan pengalaman dengan ibu lain untuk melihat apakah mengalami 
hal yang sama. Mereka perlu diyakinkan tentang keterampilan ibu mereka. Berbagi pengalaman ini memungkinkan mereka untuk melihat apakah apa yang mereka alami itu normal atau tidak. Informan menyatakan tidak pernah mencari kebutuhan informasi mereka ke perpustakaan, alasanya: (1) lokasi perpustakaan yang cukup jauh dari tempat tinggalnya; (2) koleksi perpustakaan belum mumpuni untuk topik-topik yang dibutuhkan; (3) tidak ada waktu untuk ke perpustakaan; dan (4) lebih baik membeli buku di toko buku.

Berdasarkan pendapat informan, sebenarnya lembaga perpustakaan terutama jenis perpustakaan umum untuk lebih meningkatkan kualitas dan kuantitas layanannya. Perpustakaan harus menyadari dan memahami perilaku pencarian informasi ibu primipara sehingga informasi dapat tersampaikan dengan tepat dan mengurangi kecemasannya. Menurut Dankwah et.al (2018), institusi informasi dapat melakukan pendidikan literasi kesehatan. Individu akan dibekali dengan keterampilan untuk: (1) mengetahui kebutuhan akan informasi kesehatan; (2) mengakses informasi kesehatan yang diperlukan; (3) mengevaluasi informasi kesehatan secara kritis; (4) menggunakan informasi kesehatan secara efektif dalam menyelesaikan masalah kesehatan tertentu; (5) memahami masalah hukum dan etika seputar penggunaan informasi kesehatan. Perpustakaan dan masyarakat juga dapat memperkenalkan "layanan mobile" ke desa-desa dengan membawa bahan-bahan informasi yang berhubungan dengan kesehatan secara berkala. Institusi informasi perlu berbuat lebih banyak dalam mendidik wanita muda ini tentang informasi kesehatan.

Kebanyakan ibu primipara dalam periode postpartum akan membutuhkan orang lain, profesional atau keluarga, untuk mengantisipasi kebutuhan dan pertanyaan mereka. Selain itu, mereka cenderung mendengarkan apapun yang diberitahu tentang bagaimana menjadi ibu terbaik, tetapi kemudian mereka menyadari bahwa ada banyak pendapat yang berbeda. Bahkan ada pendapat yang bertentangan dengan mitos yang selama ini berkembang di daerahnya. Informan Mutiara mengatakan bahwa "bertentangan dengan mitos, itu ilmiah karena sudah diuji para ahli dan ada penelitiannya". Berdasarkan hasil perilaku pencarian para informan, maka sebagian besar informan melakukan model pencarian informasi pemindai aktif (active scanning) dari Mckenzie (2003), yaitu mengindentifikasi yang sesuai, melaksanakan pencarian informasi yang aktif tetapi tidak memiliki rencana secara mendetail. Namun, informan Yudithia menyatakan bahwa sumber informasi diperoleh dari ibu lain yang mengalami kondisi yang sama dengannya, dan Mckenzie menyebutnya sebagai model pencarian by proxy.

\section{KESIMPULAN}

Para informan menyatakan bahwa ada kekhawatiran dan kecemasan dalam fase postpartum. Hal ini terjadi karena kurangnya informasi tentang topik seperti ASI, cara merawat anak, dan MPASI yang diberikan oleh penyedia informasi seperti tenaga kesehatan dan pustakawan. Ibu primipara merasa ini sangat kurang dalam banyak perspektif (secara medis, administratif, mengenai layanan yang ada, dan lainnya). Perpustakaan belum menjadikan prioritas layanannya dalam rangka memenuhi kebutuhan informasi ibu primipara. Adapaun rekomendasi penelitian ini, yaitu: 
1) Kebutuhan informasi secara khusus akan menyebabkan kebutuhan akan sumber informasi yang dapat dipercaya. Tampaknya selebaran dari lembaga penyedia informasi seperti rumah sakit dan perpustakaan sangat diperlukan oleh ibu baru melahirkan. Mereka membutuhkan suatu pusat informasi yang konsisten dan dikendalikan oleh para profesional.

2) Perpustakaan harus "jemput bola" dalam melayani ibu primipara. Salah satu teknologi yang mendukung penyebaran informasi adalah perpustakaan digital. Aplikasi penggunaan perangkat teknologi informasi di perpustakaan digital memerlukan kerja sama yang besar antar komponen yang saling memiliki keterkaitan, baik internal maupun eksternal.

3) Pustakawan harus lebih peka terhadap kebutuhan informasi para ibu primipara. Pustakawan berperan sebagai agen perubahan dan pemimpin yang memberikan informasi yang dibutuhkan untuk membantu organisasi mereka mencapai tujuan mereka. Pustakawan dapat menyediakan layanan informasi penting dengan menyiapkan abstrak dan indeks majalah terkini, mengorganisir bibliografi atau menganalisis informasi latar belakang dan menyiapkan laporan tentang bidang minat tertentu.

4) Para profesional berkolaborasi untuk membantu mengurangi kecemasan dan kekhawatiran ibu primipara, seperti tenaga kesehatan (dokter, perawat, konselor laktasi) dan pustakawan.

5) Ibu primipara hendaknya meningkatkan pengetahuan dengan cara lebih banyak membaca dan mencari informasi dari berbagai sumber lain, misalnya media massa tentang kehamilan, persalinan, dan nifas khususnya tentang depresi postpartum. 


\section{DAFTAR PUSTAKA}

Aston, M., Price, S., Monaghan, J., Sim, M., Hunter, A., \& Little, V. 2018. Navigating and Negotiating Information and Support: Experiences of First-Time Mothers. Journal of Clinical Nursing, 27 (3-4), 640 - 649.

Azmi, Khulul, Emilia, Ova, \& Fitrani, Herlin. 2016. Pengaruh Pemberian Konseling Terhadap Depresi pada Ibu Postpartum di Pontianak Kalimantan Barat. Yogyakarta: Universitas 'Aisyiyah Yogyakarta.

Chen, Shih-chuan. 2014. Information Needs and Information Sources of Family Caregivers of Cancerpatients. Aslib Journal of Information Management, 66: 6, 623-639.

Dankwah, Agyei, Dominic \& Adu, Stephen \& Yeboah, Esther \& Tachie-Donkor, Gloria. 2018. Establishing the Knowledge of Health Information Among Adolescent Postpartum Mothers in Rural Communities in the Denkyembour District, Ghana. Advances in Research, 14, $1-8$.

Das, Kailash Chandra \& Achary, Jeoshnamayee. 2014. Information Needs, Information Seeking Behaviour and Use of Electronic Resources by Research Scholars and Faculties in The University and Research Libraries of Odisha. Journal of Library and Information Science, 4: $4,552-566$.

Desfanita, Misrawati, \& Arneliwat. 2015. Faktor-Faktor yang Mempengaruhi Postpartum Blues. JOM, Vol.2,No.2, Juli, $998-1006$.

Ghosh, Sharmila \& Wesley, G.Y. 2002. A Special Library for Development Research - The Role of the ISS Library in Managing Information Requirements for Research. INSPEL, 36: 36, $135-145$.

Guerra-reyes, L., Christie, V. M., Prabhakar, A., Harris, A. L., \& Siek, K. A. 2016. Postpartum Health Information Seeking Using Mobile Phones: Experiences of Low-Income Mothers. Maternal and Child Health Journal, 20, 13 - 21.

Hanifah, Roidatus Salma. 2017. Faktor-Faktor yang Berhubungan dengan Kejadian Depresi Postpartum di Wilayah Kerja Puskesmas Karanganyar Kabupaten Karanganyar. Surakarta: Universitas Muhammadiyah Surakarta.

Kaye, D. 1995. Sources of Information, Formal and Informal. Library Management, 16 (5).

Loudon, Katherine, Buchanan, Steven, \& Ruthven, Ian. 2016. The Everyday Life Information Seeking Behaviours of First-Time Mothers. Journal of Documentation: Bradford, Vol.72, No. $1,24-46$.

McKenzie, P.J. 2003. A Model of Information Practices in Accounts of Everyday-Life Information Seeking. Journal of Documentation, Vol.59, No.1, 19 - 40.

Rahmawati, Anisa Fatkhur. 2018. Pengalaman Pertama Ibu Melahirkan Secara Normal Didampingi Suami. Surakarta: Universitas Muhammadiyah Surakarta.

Rotich, E., \& Wolvaardt, L. 2017. A Descriptive Study of The Health Information Needs of Kenyan Women in The First 6 Weeks Postpartum. BMC Pregnancy and Childbirth, 17(1), 385. doi:10.1186/s12884-017-1576-1. 
Slomian, J., Emonts, P., Vigneron, L., Acconcia, A., Glowacz, F., Reginster, J. Y., Oumourgh, M.,\& Bruyère, O. 2017. Identifying Maternal Needs Following Childbirth: A Qualitative Study Among Mothers, Fathers, and Professionals. BMC Pregnancy and Childbirth, 17(1), 213. doi:10.1186/s12884-017-1398-1.

Soep. 2011. Penerapan Edinburgh Post-Partumdepression Scale sebagai Alat Deteksi Risiko Depresi Nifas pada Primipara dan Multipara. Jurnal Keperawatan Indonesia, Vol.14, No.2, Juli, $95-100$.

Sugiyono. 2010. Metode Penelitian Pendidikan: Pendekatan Kuantitatif, Kualitatif, dan R\&D. Bandung: Alfabeta.

Sulistyo-Basuki. 2010. Metode Penelitian. Jakarta: Penaku.

Wilson, T.D. 1981. On User Studies and Information Needs. Journal of Documentation, 37 (1), 3 -15 . 